\title{
CORPO E HABITUS: DAS NECESSIDADES DE INSURGÊNCIA DOS CORPOS NEGROS
}

\author{
Rosangela Souza da Silva ${ }^{1}$
}

\begin{abstract}
Resumo: O texto resulta de reflexões em torno dos conceitos de corpo e habitus, em diálogo com uma experiência vivenciada por duas mulheres negras atendidas por um motorista de aplicativos, na cidade de Salvador, quando saíram de uma restaurante sexta-feira à noite. Além de realizarmos discussões que confirmam que a nossa relação com o mundo é corpórea, levando em conta as percepções do motorista sobre as professoras negras, que determinou a interseccionalidade entre raça e classe, demonstramos também como a força do habitus amalgama distinções, sentidos e significados que inculcam maneiras de compreensão e explicações do mundo social.
\end{abstract}

Palavras-Chave: Corpo. Corpos Negros. Habitus.

\begin{abstract}
The text results from reflections around the concepts of body and habitus, in dialogue with an experience lived by two black women attended by an application driver, in the city of Salvador, when they left a restaurant Friday night. In addition to conducting discussions that confirm that our relationship with the world is corporeal, taking into account the driver's perceptions of black teachers, who determined the intersectionality between race and class, we also demonstrate, as the strength of habitus amalgamats distinctions, meanings and meanings that inculcate ways of understanding and explaining the social world.
\end{abstract}

Keywords: Body; Black Bodies; Habitus.

\section{Introdução}

O presente artigo faz uma abordagem sobre os conceitos de corpo e habitus, a partir das leituras de Bourdieu (2007, 2011) e Merleau-Ponty (1999), dialogando também com autores/as como Setton (2002), hooks (2005), Gomes (2008) e Rabelo (2012), com a finalidade de problematizar uma situação vivenciada por duas mulheres negras ${ }^{2}$, com um motorista do transporte $\mathrm{Uber}^{3}$, na cidade de Salvador/BA.

1 Doutora em Educação pela Universidade Federal da Bahia - UFBA. Professora Assistente da Universidade Federal do Recôncavo da Bahia - UFRB. Email: rosangelasilva@ufrb.edu.br.

2 Ambas são docentes do ensino superior e são engajadas nas lutas contra as desigualdades raciais, de gênero e quaisquer formas de discriminações.

3 É uma empresa multinacional norte-americana, prestadora de serviços eletrônicos na área do transporte privado urbano e baseada em tecnologia disrruptiva em rede, através de um aplicativo $E$ hailing que oferece um serviço semelhante ao táxi tradicional, conhecido popularmente como serviços de 
Em uma sexta-feira à noite, duas professoras saíram para jantar em um restaurante localizado no bairro Rio Vermelho ${ }^{4}$, em Salvador, para comemorarem a finalização do Pós-Doutoramento de uma delas. O restaurante escolhido é frequentado, majoritariamente, por pessoas brancas. Naquela noite, a única mesa composta por pessoas negras era a ocupada pelas duas professoras.

O figurino da noite era roupas brancas. Uma das professoras usava saia e camiseta; a outra, vestido. Como acessórios, as duas usavam brincos e colares. Uma, estava com o cabelo crespo e solto e a outra usava um torço na cabeça. Tal descrição detalhada da maneira como estavam vestidas se faz necessária, porque é, a partir desta configuração estético-corporal, que se constituiu um diálogo (tenso em determinados momentos) entre as professoras e o motorista, após a saída delas do restaurante, no translado para casa.

As professoras, já no interior do carro, depois de serem saudadas com um 'boa noite', são interpeladas, efusivamente, pelo motorista, com a seguinte pergunta: “Estavam trabalhando vendendo acarajé?". Tal questionamento sobre o que estavam fazendo no interior do restaurante deixaram-nas estupefatas, inicialmente, levando-as a inquiri-lo imediatamente: “Trabalhando vendendo acarajé, por quê”? Ele respondeu: "Porque estão saindo do restaurante, e as roupas que estão usando parecem de baianas do acarajê". Elas retrucaram: “Mas estamos usando roupas comuns: saia, camiseta, vestido. Estamos saindo de um restaurante. O que lhe faz pensar que somos baianas de acarajê"?". Ele retrucou novamente, imerso na sua certeza: “Ah!!!! Mas vestidas desse jeito, com este torço... Aqui na Bahia, não se vê muita gente assim, só as baianas de acarajé."

\footnotetext{
"carona remunerada". Disponível em:

https://www.google.com.br/search?newwindow=1\&q=transporte+uber+o+que+é\&oq. Acesso 17 de nov. de 2020.

4 É considerado um bairro nobre de Salvador e está localizado entre Ondina e Amaralina. Nesse bairro, de intensa vida noturna, estão situados luxuosos hotéis e pousadas. Disponível em: https://pt.wikipedia.org/wiki. Acesso 17 de nov. de 2020.

${ }^{5}$ As professoras não se sentiram ofendidas com a ligação da estética delas com as baianas de acarajé. As baianas são mulheres negras que, historicamente, tiveram um papel fundamental na preservação da tradição afro-brasileira no Brasil, bem como na manutenção e sobrevivência de várias gerações de famílias negras.
} 
Da forma mais educada possível, as professoras tentaram situá-lo em relação à presença delas no restaurante (estavam comemorando uma conquista na vida de uma delas, o Pós-doutoramento). Demonstraram o equívoco das suas percepções sobre as roupas por elas utilizadas. Explicaram que tais impressões são visões essencializantes de corpos negros; as suas roupas não deveriam ser enquadradas em um determinado grupo; podem estar afiliadas a variados outros grupos sociais, culturais, profissionais, religiosos etc. Todavia, por conta da cor da pele delas, ele estava confundindoas com as profissionais que vendem acarajé. Notabilizam também, que, no atual contexto, o uso de torços/turbantes por mulheres negras e, às vezes, por que mulheres brancas não devem colocar essas pessoas (principalmente as negras) apenas no lugar de baianas de acarajé.

Para finalizar, afirmaram - com veemência - que as baianas são referências na vida delas. Tratam-se, em sua maioria, de mulheres negras pelas quais as docentes têm um inestimável respeito e estima. Tais considerações, apresentadas pelas professoras, provocam uma sucessão de argumentos pífios do motorista, tais como: a) "Não estou falando porque as senhoras são negras. Eu sou branco, mas na minha família tem muitas pessoas negras"; b) “Eu tenho muitos amigos negros"; e c) “A pessoa não vai advinhar que as senhoras (está na cabeça dele que as pessoas com aqueles corpos, leia-se cor) estão em um restaurante comemorando um pósdoutorado".

Noutras palavras, ele não admitiu que pessoas com aqueles corpos e de pele negra poderiam frequentar aquele restaurante para comemorar um pós-doutoramento.

Como percebemos, a situação vivenciada e os argumentos apresentados pelos sujeitos nela envolvidos requerem uma discussão mais profunda sobre o ocorrido. Assim, dada às considerações iniciais sobre o fato, ampliaremos as reflexões, salvaguardando que os discursos (FOUCAULT, 2002) e as práticas sociais dos sujeitos são de suma importância para a compreensão do mundo social, operando como um termômetro que demonstra percepções, distinções e sentidos de tentativas de compreensão e explicações da realidade. 


\section{Corpo e Corpo Negro}

Os diálogos com estudos sobre o tema corpo demonstraram-nos um corpo marcado por instabilidades e impregnado de mundo, pois o "[...] acesso ao mundo é possibilitado pelo corpo e, o homem, com seu corpo se dirige ao mundo e o apreende" (MERLEAU-PONTY, 1999, p. 115). Tal assertiva mostra os significados e a importância do corpo na relação com o mundo, pois, ao forjarse no mundo, esse corpo torna-se mais complexo, apreendendo-o, carregando marcas de pertenças históricas, socioculturais e políticas do mundo vivenciado, em eterno devir.

Outrossim, “[...] toda ação humana é corporalidade encarnada, isto é, não pode se dar desvinculada deste, o corpo é veículo e solo de qualquer manifestação ou percepção." (MERLEAU-PONTY, 1999, p. 110). Assim, inferimos que inexiste ação humana sem corpo, logo, se não há corpo, não há ação humana, impedindo “qualquer manifestação ou percepção" do humano.

Levando em conta a compreensão de corpo abordada por MerleauPonty, Rabelo (2012, p. 3) afirma: “[...] o corpo é o fundamento de nossa experiência no mundo, dimensão mesma do nosso ser." Desta forma, pensar o corpo é não separá-lo do mundo, pois, ao ser "fundamento da nossa experiência no mundo". Ademais, esse se consagra enquanto pilar fundamental para as apreensões da cultura, da história, das infinidades de práticas sociais e afetivas que (re) desenham o mundo social.

De forma mais premente, tecer considerações sobre a magnificência do corpo, no âmbito das relações homem-mundo, faz-se muito importante para a compreensão de todo o tecido social, atentando-nos para as vulnerabilidades do corpo, que marca a nossa presença no mundo. No que chamamos de mundo, inexiste uma percepção única de corpo e os "quadros de referência" (CERTEAU, 2002) para situar os corpos em quaisquer culturas envolvem dramas e tramas, que - muitas vezes - não se indicam ao “estrangeiro", o outro, que não experiencia e ou experienciou aquele mundo.

Para Merleau-Ponty (1999, p. 127): “[...] Se o corpo pode simbolizar a existência, é porque ele a realiza e é sua atualidade". Se a existência é realizada através do corpo, o que diremos de corpos que vivenciaram/vivenciam processos de desumanização e de descrédito, das 
mais variadas formas de violência e de tentativas de gestão das suas corporeidades nos espaços em que transitam (escolas, universidades, mercado de trabalho, espaços de lazer, religiosos etc.).

Destarte, na situação vivenciada pelas duas professoras, o existir para um mundo a partir de um corpo se realiza de forma enviesada, pois os corpos negros, diuturnamente, são desrespeitados, aviltados e são os mais suscetíveis a todos os tipos de violência. Conquanto afirma Silva (2009, p. 48): "O corpo é sempre um corpo situado, marcado socialmente por sua condição de classe, por sua existência única e diversa, porém social." Para além da afirmação do marcador de classe que se inscreve no corpo, em sociedades racializadas como a brasileira, o "fardo da raça" aprisiona os corpos de homens e mulheres negras, baseadas em lógicas racistas que se incrustam as relações sociais. Para hooks (2005, p. 8):

Em uma cultura de dominação e antiintimidade, devemos lutar diariamente por permanecer em contato com nós mesmos e com os nossos corpos, uns com os outros. Especialmente as mulheres negras e os homens negros, já que são nossos corpos os que frequentemente são desmerecidos, menosprezados, humilhados e mutilados em uma ideologia que aliena. Celebrando os nossos corpos, participamos de uma luta libertadora que libera a mente e o coração.

Os efeitos nocivos dessa cultura de dominação, no atual contexto, reatualizam-se as formas de discriminação, advindas também de sociabilidades etnocêntricas e excludentes. Se tomarmos como parâmetro o período escravocrata e pós-escravidão, percebemos que foram deixadas marcas indeléveis nos corpos negros, que até hoje se refletem nas relações desses sujeitos com suas corporeidades.

A autora Gomes (2008), em sua obra, Sem perder a raiz: corpo e cabelo com símbolo da identidade negra faz a seguinte consideração em relação à identidade, a partir da estética corporal do negro:

[...] o cuidado com a estética corporal para o negro também pode significar a reversão de uma imagem negativa construída socialmente sobre o seu grupo étnico-racial. Diante de uma inevitável incorporação de 
uma representação negativa de si mesmo, construída pelo outro e por uma condição histórica e social da desigualdade, o negro e a negra aprendem a manejá-la pelo avesso (GOMES, 2008, p. 141).

Notadamente, as interpretações, a partir do campo das relações etnicorraciais, demonstram-nos que as/os negras/os, ao manipularem os seus corpos para a reafirmação de suas identidades, engendram uma reversão de valores, normas e formas de ser e estar no mundo. Deliberadamente, os significados sociais auferidos aos corpos negros colocam-os em desvantagens nos espaços em que circulam, fragilizando os processos de formação das identidades desses sujeitos, fortalecendo o sentimento de recalque e consolidando o afastamento dos referenciais socioculturais de pessoas negras com os seus pares, tornando-as alheias à importância de seus fazeres, saberes, vestires e falares.

$\mathrm{O}$ argumento do motorista: "Não estou falando porque as senhoras são negras. Eu sou branco, mas na minha família têm muitas pessoas negras" mostra algumas peculiaridades, inerentes às suas apreensões do mundo social. Fica explícito, que ele determina "quem é quem", a partir da seguinte configuração da situação: ele, o branco, que se autoriza a nomear duas mulheres negras, que saem de um restaurante, de "vendedoras/baianas de acarajé. Mas, não se permite ser questionado acerca das suas "verdades", quiçá, pensar na sua atitude preconceituosa e racista, porque "tem na sua família muitas pessoas negras".

Para nós, a maneira negativa de apresentar negros/as, no Brasil, demanda a necessidade de construir outras formas de se educar no Estado brasileiro, em que as referências identitárias e corpóreas oficializadas contenham histórias positivadas de todos que compõem a sociedade, em especial dos negros e indígenas.

As percepções e os tratamentos destinados aos corpos são socioculturalmente construídos, interligados aos processos históricos de cada sociedade. Existem as singularidades individuais, mas, cada corpo carrega valores, comportamentos, marcas das leis e das crenças, que ordenam as várias dimensões da vida das pessoas a partir dos seus grupos de pertença (GONÇALVES, 2012). 
Por conseguinte, ao insurgirem os seus corpos contra discursos dogmáticos e normatizadores, como se apresentou o do motorista do Uber, as pessoas negras perspectivam edificar outras referências também, com as quais possam ser comparadas. É importante que essas comparações se assentem em uma matriz plural e dinâmica, como se configura o mundo social.

Desse modo, potencializar as discussões sobre os sentidos e significados do corpo no mundo necessita da construção de uma matriz perceptiva que consiga matizar interesses de várias classes, culturas e pertenças, que incorporem o trânsito enquanto pontos de partida e chegada para os corpos, contrapondo-se a processos essencializantes que edificam fronteiras e tentam danificar a relação homem-corpo-mundo no seu infinito devir.

\section{A Força do Habitus}

Perceber determinados grupos sociais e etnicorraciais a partir de um espectro essencialista, infelizmente, ainda é lugar comum em nossa sociedade. A miopia de alguns sujeitos sociais, diante de outras formas de sociabilidades vivenciadas por esses grupos, colocando-os em situações desconfortáveis e degradantes, culmina, às vezes, em ações litigiosas, agressões verbais e/ou físicas.

Se pensarmos tal prática social a partir do habitus,

[...] como um sistema de esquemas individuais, socialmente constituído de disposições estruturadas (no social) e estruturantes (nas mentes) adquirido nas e pelas experiências práticas (em condições sociais específicas de existência), constantemente orientado para funções e ações do agir cotidiano (BOURDIEU, 2011, p. 164).

Como a percepção do mundo social a partir do habitus quase impossibilita apreender o movimento do mundo social, pois, ao "orientar funções e ações do agir cotidiano", estrutura o lugar ocupado pelos dominados e dominantes, em que os primeiros grupos estão subordinados aos segundos. Logo, o habitus está envolvido nas relações de poder. 
Bourdieu (2011) notabiliza que o habitus é inculcado, organizando uma percepção do mundo social, baseando-se em oposições “[...] alto/baixo, rico/pobre etc." (2011, p. 164). Nesse sentido, a pergunta do motorista: Estavam trabalhando vendendo acarajée?". Sem sombra de dúvida, nessa indagação, contém minúcias que circunscrevem os sujeitos (aqui as professoras negras) em determinadas classes ${ }^{6}$, calcadas em uma polaridade, que, por conta do habitus, relaciona a cor da pele negra às profissões de menor prestígio em nossa sociedade, intuindo que a presença das professoras no restaurante estaria ligada ao mundo do trabalho, isto é, a vender acarajé.

Para tanto, o habitus, que tem a capacidade de produzir práticas; organiza a percepção do mundo social; identifica a mediação entre indivíduo e sociedade, é considerado como uma subjetividade socializada (BOURDIEU, 2007), imprimindo em todo o tecido social, classificações, gostos e formas de pensar.

Ao se refletir sobre a afirmação do motorista: “ $A$ pessoa não vai adivinhar que as senhoras estão em um restaurante comemorando um pósdoutorado", percebe-se que, deliberadamente, o que fundamenta tal fala do motorista é uma cadeia de informações balizadas em distinções captadas no mundo social. O motorista não teria condições de avançar nas suas conjecturas sobre os motivos da presença das professoras, pois, no habitus.

Cada condição é definida, inseparavelmente, por suas propriedades intrínsecas e pelas propriedades relacionais inerentes à sua posição no sistema de condições que é também, um sistema de diferenças, de posições diferenciais, ou seja, por tudo o que a distingue de tudo o que ela é e, em particular, de tudo o que lhe é oposto: a identidade social define-se afirma-se na diferença (BOURDIEU, 2011, p. 164).

Destarte, se não houve apreensões diferentes sobre os corpos negros das professoras é porque a produção de práticas sociais (que são classificáveis) no habitus, operam também “[...] com sistemas de sinais socialmente

\footnotetext{
${ }^{6}$ Classe, no texto O habitus e o espaço dos estilos de vida, de Bourdieu (2007), não é entendido por critérios econômicos.
} 
qualificados, que podem ser concebidos como "distintos" ou "vulgares" (BORDIEU, 2011, p. 164).

Assim, os trajes (acreditamos que, principalmente, o torço) daquelas mulheres negras não se "enquadram", a partir dos sistemas de sinais, ditos qualificados, pois, no modus operandi da nossa sociedade, no que tange aos elementos da cultura negra, os seus símbolos e signos são reificados.

Ademais, o fato de estar no restaurante, comemorando o Pósdoutorado contradiz uma possível lógica sob a qual pode está calcado o habitus. O referido é: “[...] um instrumento conceptual que auxilia a apreender uma certa homogeneidade nas disposições, nos gostos e preferências de grupos e/ou indivíduos produtos de uma mesma trajetória social" (SETTON, 2002, p. 64). Por se tratar de duas mulheres negras e mediante as tramas complexas e pouco democráticas, equitativas e igualitárias que envolvem as relações socioculturais e etnicorraciais no Brasil, tornou-se difícil para o motorista extrapolar e prescindir de "[...] certa homogeneidade de gostos e preferências [...]" (SETTON, 2002), que se remetem ao habitus.

Aos reveses dessa lógica, a autora Setton (2002) afirma que, fundamentalmente, o conceito de habitus busca "[...] romper com interpretações deterministas e unidimensional, recuperando a noção ativa dos sujeitos como produtos da história e de experiências acumuladas no curso de uma trajetória individual" (SETTON, 2002, p. 65). De todo modo, se faz necessário romper com o habitus, colocando-o sempre em suspeição, para que a experiência como inevitabilidade não persiga a história de determinados grupos.

Enfim, cremos que seja, de fundamental importância, trazer à baila a situação vivenciada pelas professoras, para que a força do habitus não "eternize" papéis e lugares para os indivíduos no mundo social, porque, para nós, as reflexões aqui apresentadas, quiçá, oportunizarão outras apreensões da dinâmica social.

\section{Conclusão}

As reflexões sobre corpo e habitus, no presente texto, levaram em conta a situação vivenciada pelas professoras negras. Assim, ao nos 
remetermos aos conceitos de corpo e habitus para problematizar e compreender tal situação, atentou-se para as percepções e experiências do outro.

O primeiro cuidado foi com o lugar ocupado pelas professoras. Essas desempenharam um papel educativo precípuo no diálogo efetuado com o motorista. Elas explicaram porque estavam no restaurante; destacaram que as roupas que usavam eram comuns e não podiam determinar quem eram elas, do ponto de vista profissional; salientaram que a cor da pele é um signo que ainda serve de parâmetro para informar os lugares ocupados por alguns indivíduos nas estruturas sociais, mas, de maneira alguma, isso pode ser considerado determinante. Isso, inclusive, o atualizou quanto às trocas realizadas do ponto de vista da estética (também de outras formas), entre negros e brancos, a exemplo de muitas mulheres brancas usando turbantes.

As professoras, através de seus posicionamentos, têm suas trajetórias marcadas por diversos momentos de desrespeito dos seus corpos, com sua intelectualidade, enfim, vivenciam uma ética e uma política dentro de uma sociedade que teima em aprisioná-las em determinados papéis sociais.

Quanto ao motorista, iniciou o diálogo (acreditamos querendo ser sociável) com as professoras, a partir da sua experiência com o mundo social. Assim, ele surpreende as professoras com a primeira pergunta; explica para elas o porquê das suas percepções; e, de forma rápida, tenta aniquilar os argumentos apresentados por elas, a partir de uma retórica sem fundamentos. Respaldando-se em um habitus, que opera com distinções, invalida as experiências acumuladas pelos sujeitos e se apega ás interpretações deterministas.

Dada à situação apresentada, para nós, se faz necessário que os indivíduos recorram a outras referências para realizarem as suas leituras do mundo social, mesmo a partir do habitus, porque esse também é “[...] incessantemente confrontado com experiências novas e incessantemente afetado por elas (BOURDIEU, 1992, p. 108).

Isso posto, ao compreendermos a partir das leituras, que habitus, corpo e mundo social são devires, cabe também aos sujeitos saírem das suas redomas, derrubando quaisquer fronteiras que lhes deixem à margem das 
mais variadas maneiras de ser e estar no mundo, que evocam novas aprendizagens, percepções e sentidos.

\section{Referências}

BOURDIEU, Pierre. O habitus e o espaço dos estilos de vida. In: A distinção: crítica social do julgamento. São Paulo: EDUSP, 2007.

CERTEAU, Michel. História de Corpos. Proj. História. São Paulo, no 25, 2002, p. 407-411.

GOMES, Nilma Lino. Sem perder a raiz: corpo e cabelo como símbolos da identidade negra. 2. ed. Belo Horizonte: Autêntica, 2008.

hooks, bell. Alisando nosso cabelo. In: Revista Gazeta de Cuba. Trad. Lia Maria dos Santos. Unión de Escritores y Artista de Cuba, jan./fev. de 2005. Disponível em: coletivomarias.blogspot.com/.../alisando-o-nossocabelo. html. Acesso em 07 de nov. de 2013.

MERLEAU-PONTY, Maurice. O corpo. In: Fenomenologia da percepção. Trad. Carlos Alberto R. de Moura. São Paulo: Martins Fontes, 1999.

RABELO, Míriam C. M. Merleau-Ponty e as Ciências Sociais: corpo, sentido e existência. Disponível em: http://docslide.com.br/documents/merleauponty-e-as-ciencias-sociais-corpo-sentido-e-existencia.html. Acesso em 14 mar. de 2017.

SETTON. Maria da Graça Jacintho. A teoria habitus em Pierre Bordieu: uma leitura contemporânea. Revista Brasileira de Educação. maio/jun/jul/ago, no 20, 2002, p. 60-70. Disponível em: https://doi.org/10.1590/S141324782002000200005 . Acesso em 14 mar. de 2017.

Recebido em 20 de novembro de 2020

Aceito em 15 de dezembro de 2020 